\title{
From traditional Construction Industry Process Management to Building Lifecycle Management
}

\author{
Ada Malagnino ${ }^{1}$, Giovanna Mangialardi ${ }^{1}$, Giorgio Zavarise ${ }^{1}$, Angelo Corallo $^{1}$ \\ ${ }^{1}$ Department of Engineering for Innovation, University of Salento, Italy \\ ada.malagnino@unisalento.it \\ giovanna.mangialardi@unisalento.it \\ giorgio.zavarise@unisalento.it \\ angelo.corallo@unisalento.it
}

\begin{abstract}
Building Information Modeling (BIM) is an innovative approach based on a virtual model, which allows to manage all the information about the building. This approach is applicable to all the phases of the building process, but many surveys show the lack of BIM implementation in the use e maintenance phases. The BIM use in the management phase, represents a unexpressed potentiality, a differentiating factor compared to Product Lifecycle Management (PLM), a holistic approach able to oversee the whole life cycle of a product and the information connected with it, widespread and consolidated in the manufacturing sector. Starting from this assumptions, in an empirical study, the paper presents a qualitative investigation into the current situation of the processes management of the constructed heritage in a French real estate company. The case study proposes the integration of the PLM and BIM approaches, that could be defined as Building Lifecycle Management (BLM), in order to close the gap of the traditional method.
\end{abstract}

Keywords: BIM, PLM, BLM, Management, AEC Industry

\section{Introduction}

The increased attention given to sustainability and use of new technologies in the construction industry requires new approaches that take into account the entire life cycle of the building. The building sector, in fact, accounts for about $40 \%$ of final energy consumption in EU [1] and it is the largest consumer of raw materials in the world, with less than a third of recycled waste materials [2]. To this end, several applications and researches are based on the need to innovate traditional building processes from both methodological and technological point of view. In the Architecture, Engineering and Construction (AEC) Industry this trend is reflected in the Building Information Modeling (BIM), where "M" has also the meaning of Model and Management [3], widespread in many contexts such as USA and UK or in the countries from Asia-Pacific [4] and it is taking off in others nations, like in Italy [5]. Application of BIM to building processes responds to a strong need to bring innovation to construction industry, that is generally 
slow to change and currently suffers the economic crisis effects. The main resistances lie in the inability to regulate the production of an asset that cannot be standardized and in the complexity of ensuring interoperability among the various actors involved in the process. Strong parallelism, also reported in many interdisciplinary studies in literature $[6,7,8]$, was found between BIM, or rather BLM, and PLM, an innovative and holistic approach used by manufacturing industry to manage the product life cycle. PLM, by integrating data, processes, business systems, and people [9], can represent an opportunity to extend its methodological and technological maturity to the buildings whole life cycle management. In this frame, the opportunity to study both PLM and BIM approaches, by highlighting the strengths, weaknesses and possible contact points, results to be an interesting challenge for the built heritage of a major French real estate company (I3F Group), which manages the entire life cycle of its buildings. The case study is justified by the processes complexity, the multiplicity of the actors involved, the large number of used software applications, that cause high risk of errors and loss of time and costs. The main interest of the company is to improve the built heritage management and this study gives a contribution to achieve this result by a qualitative research that lead to a critical analysis of the traditional management processes. This research, by analysing the "As Is" of the French company activities management, aims to integrate BLM approach to optimize processes, by proposing a new conceptual model that would benefit from BIM, thanks to the specificities linked to the building process, but also from PLM, in relation to its consolidated experience in the whole process management in the industrial sector. The paper is divided into 6 Sections. Sect. 2 presents a brief review of the literature, of the technologies on the market and of their application for the management and maintenance of other similar cases. Sect. 3 introduces the research settings and method. Sect. 4 presents the empirical case study and Sect. 5 presents findings which are structured according to the proposed conceptual model (To $\mathrm{Be}$ ), concluding the paper with a discussion on the challenges identified and on future developments.

\section{Background}

The Product Lifecycle Management is a strategic business approach for the effective creation, management and use of corporate intellectual capital, from a product's initial conception to its retirement [10]. PLM systems support the product management during its life cycle, facilitating coordination and collaboration among different stakeholders. Hence, PLM is not only a software, but it is a methodology that unifies management dimensions (processes), economic dimensions (costs and revenue), technical dimensions (activities and staff) and technological ones (IT systems) [11]. "Currently, PLM is being used in a wide range of industries. It is used in discrete manufacturing, process manufacturing, distribution and service industries, as well as in research, education, military and other governmental organizations" [9]. The Building Information Modeling seems very similar to the Product Lifecycle Management [12]. BIM is "the process of creating and using digital models for design, construction and/or operations of projects", according to Succar [13]. It is centred around an Information Model, which is 
"the virtual representation of the physical characteristics of a facility from inception onwards. It serves as a shared information repository for collaboration throughout the facility's lifecycle" [14]. Therefore, BIM can be viewed as a virtual process that allows all design team members (owners, architects, engineers, contractors, and suppliers) to collaborate more accurately and efficiently than using traditional processes [15]. Integration between BIM and PLM is a subject of much discussion as several important international studies show $[12,16,17,18]$. Both BIM and PLM approaches are based on the idea of managing the whole product life cycle, so that phases and actors of the process become linked. Each approach is focused on a 3D virtual model that contains all the necessary information about the product, which can be a building or an infrastructure for BIM and an industrial product for PLM. Actually, the most widespread BIM technologies are fully concentrated on visualisation and internal consistency checking to detect errors during the design and construction process [19]. Compared to PLM, which is applied to all the phases of product life cycle, this represents only a section of the entire cycle $[12,20]$. Recently, consistent efforts have been made to enrich the traditional 3D BIM with the $4 \mathrm{D}, 5 \mathrm{D}$, or even $6 \mathrm{D}$ and $7 \mathrm{D}$ dimensions, by trying to cover all phases of the building life [21]. This solution has been named Building Lifecycle Management or Unified Project Management (UPM) [22, 23]. BLM is an emerging concept which aims to consolidate design, engineering, construction, financial aspect, energy usage and facilities data in a central database for a holistic picture of a building process [24]. Through a Building Lifecycle Platform (BLP), BLM seeks to improve the level of information sharing among stakeholders at different phases of the project life cycle and to reduce the building information exchange barriers [25]. BLM could be seen as a way of developing a project strategy on its full life cycle and providing a mechanism of an information flow integrated management in the framework of an integrated IT environment. It aims to transform separate contractors into teams and separate tasks into processes in order to obtain a more effective and less costly implementation of such operations in the whole construction project life cycle [21]. To achieve this result, benefits and best practices issued from PLM are used to enhance BIM towards BLM [26, 27]. As regards management process, BIM should gain from PLM a more detailed definition of procedures, responsibilities and data structure, given that there is a lack of document management, version and status control and traceability of information. Integration of PLM methodologies in BIM system could facilitate capturing and coordination of the current and past projects information, as well as it could optimize the resources and strategic goals of an enterprise. This can enhance the decision-making efficiency, promote better use of resources and support agile problem-solving. Such a comprehensive information consolidation along with business intelligence tools facilitate uncovering, use and reuse of best practices in design, requirements management and project workflows. Change management features of PLM solutions enable tracking design, fabrication and construction changes in projects and ensure consistency of working information by different project entities [28]. The relation between BIM and PLM can therefore be considered inclusive and BLM represents the model that ensures this inclusion [27]. Building owners and operators are driving the AEC industry to achieve higher levels of BLM adoption by demanding process improvements and technological innovations. As the use of BLM grows, so does 
the amount of digital project information. As a consequence, companies need a more integrated approach for capturing, managing, and sharing data among increasingly different project teams, in order to maximize the business benefits of BLM processes. For this purpose, several PLM platforms are adapted to be used for AEC Industry projects, demonstrating the importance of integration between a consolidated approach and Building Information Modeling. For instance, Lascom (a software publisher in the field of PLM data management) met CSTB (Centre Scientifique et Technique du Bâtiment) in 2011 with the Centre de Recherche Finlandais VTT as a partner, to create Lascom AEC BIM Edition web platform. The aim of the project was to adapt the proven PLM process for managing documents online with business workflows. Another example is Dassault Systèmes 3DEXPERIENCE platform, which offers PLM applications that leverage BIM data for the AEC Industry. Also Siemens dedicates a section to BIM, through Siemens PLM for AEC and Infrastructure solution, that supports building process from design phase to maintenance phase. The result of the BLM innovation process is that big companies like Hickory Group in Australia and Skanska Group in Finland [29] are becoming aware of the benefits that integration between PLM best practises and BIM could bring not only in the initial phases of the process (design and construction), but also during use and maintenance phase $[30,31]$ and apply PLM solution to manage data.

\section{Research settings and method}

On the base of the literature state of art, BIM approach is not considered sufficient to optimize the management of a real estate company's construction heritage, and PLM is not adapted to the construction industry peculiarities. Starting from this evaluations, this research aims to integrate BIM and PLM approach to give a BLM setting to Immobilière $3 \mathrm{~F}$ activities, that represents the case study of the present research. The complexity and variety of its activities in all the construction industry process management make it a good empirical example for the analysis of the application of BLM. A qualitative research on the company management processes was carried out, pinpointing all the activities and their related actors, divided into internal and external actors. Furthermore, for each activity a detailed study on software utilized by each actor was carried out. Data collection, which began in September 2014 and finished in December 2014 during a period of internship in $3 \mathrm{~F}$ offices in Paris, involved analysis of project documents (project plans, contract documents, reports), qualitative observation of the activities as a participant actor and semi-structured interviews with company staff. In this way, the researcher had a firsthand experience with participants and had the possibility to record a lot of information. Face-to-face interviews involved unstructured and open ended questions, by covering a range of topics related to the research problem, such as information exchange method, documents management, interactions with external actors, technologies. Twelve employees with different roles were interviewed and each interview, which took place at the end of the period of internship, lasted approximately thirty minutes (see Tab. 1). From the data collected, process workflow processes and information management were mapped, and the set of information was systemized, 
crossing the various phases of the process (conception and design, construction management, use and maintenance, demolition or refurbishment) with actors and software.

Tab 1. Interviewees

\begin{tabular}{|c|c|c|}
\hline Sector & Title & \#Interviewed \\
\hline Urban Development & $\begin{array}{c}\text { Architecture and } \\
\text { Urban Planning Manager }\end{array}$ & 1 \\
\hline Real estate management & Delegated Project Manager & 1 \\
\hline $\begin{array}{c}\text { Construction operations } \\
\text { management }\end{array}$ & Project Manager & 3 \\
\cline { 2 - 3 } Urban Renovation & Project Manager Assistant & 3 \\
\hline \multirow{2}{*}{\begin{tabular}{c} 
Project Manager \\
\hline
\end{tabular}} & Project Manager Assistant & 2 \\
\hline
\end{tabular}

The analysis of the management processes enabled the individuation of the bottlenecks that were worked out in order to achieve a better organization and, as a consequence, time and costs savings. The PLM system provides a guidance on system requirements, above all as regards phases automation, through standard procedures definition. A solution for each bottleneck was detected among the system features and a management process conceptual model was proposed to improve company activities quality.

\section{Case study}

The case study is represented by a French real estate company, Immobilière 3F, that manages 245.000 social housing units, commercial premises and residential homes in France. In detail, I3F deals with buildings construction, real estate management, buildings maintenance, urban renewal, territorial development, apartment rental and selling. The company plays different roles according to the different activities. It is, in fact, owner, developer, contracting entity, supervisory body, management body, etc. and it uses its internal organisational set-up for managing all the processes, from the beginning to the end. In the generic process some external actors are involved, such as territorial authorities, architects and engineers, construction company and other professionals. I3F previously expressed its interest in BIM and carried out a feasibility study to implement the BIM approach to its activities. This empirical study aims to give a further contribute by including PLM best practises through a customized BLM method. To this purpose, a detailed analysis was carried out specifically on new construction process, rather than renovation or urban renewal process, because it involves a greater number of actors and phases and it is more comprehensive. Data collected during the qualitative research have been processed firstly to understand the As Is, by finding and mapping the relationships between activities, actors involved an software used (fig.1), secondly to identify the issues that caused waste of time and delays, increasing of costs and risks of errors, communication difficulties and lack of documentation traceability. Based on these results, a study of PLM requirements is carried out in order to acquire 
some best practise that could benefit the company management processes. PLM requirements that have been identified as possible solutions for the company As Is issues, have been adapted to the construction industry and customized to the case study specificity.

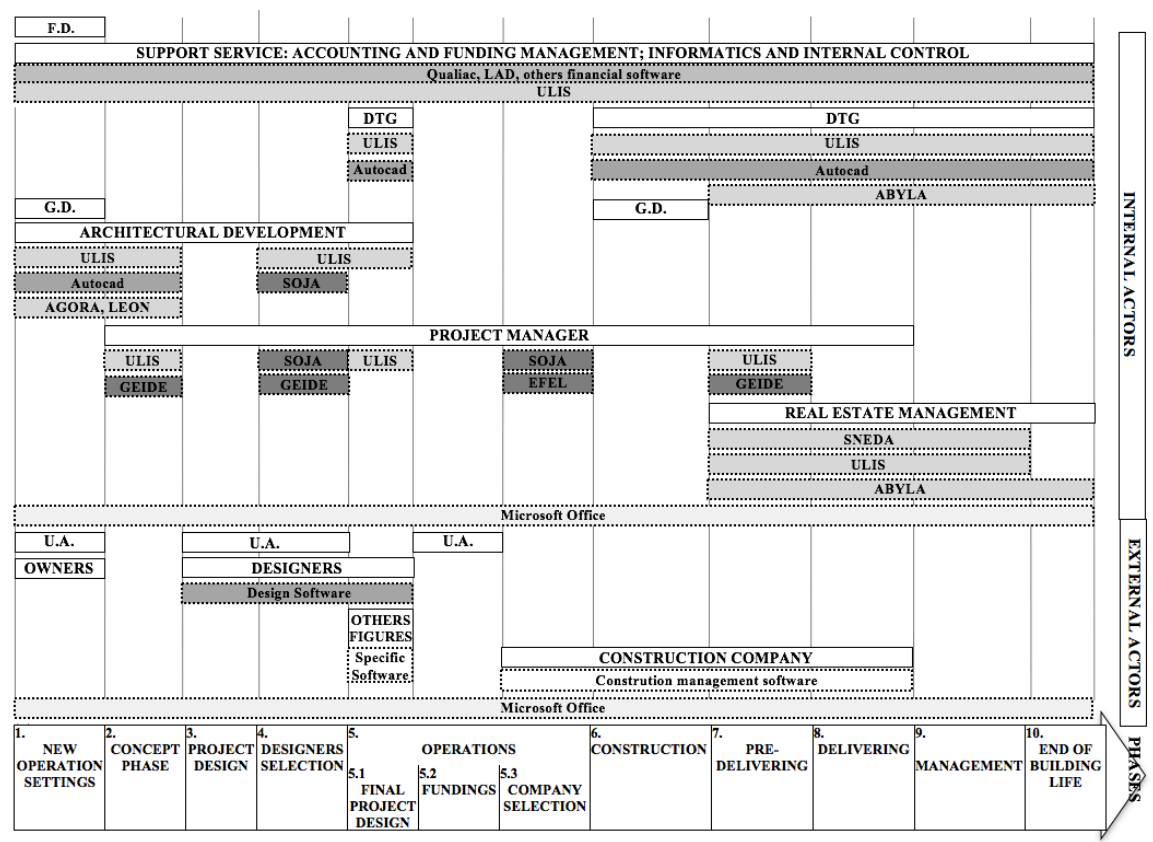

DTG: Technical Team; F.D.: Financial Direction; G.D.: General Direction; U.A.: Urban Authorities.

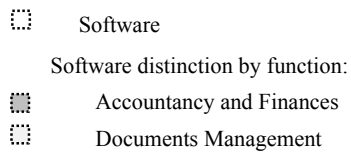

Fig. 1. "As Is" of the French company activities management

As shown in fig. 1, where process phases, actors and software are systemized in order to underline interactions and to have a better comprehension of the case study complexity, the company uses many software applications not interoperable and each one for a specific activity. For instance, GEIDE is an online archive available by the staff; LEON is a tool for budget evaluation; SOJA is used to manage purchases; etc. ULIS is the only management tool that is used in different activities, thanks to specific modules for each thematic area, i.e. construction activities, real estate management, financial and accountancy management, technical management. Data analysis points out that technological systems are not linked and management processes are not automated. In addition, each project manager uses Excel spreadsheets, data are entered manually and documents exchange is done on paper form or through .pdf files. Another bottleneck is represented by the lack of automatic check on files versions uploaded and standard format. As regards the second result of data analysis, the authors propose a 
new process conceptual model based on an integrated BIM and PLM environment, named BLM environment, by identifying the main solutions at the above-mentioned bottlenecks, following described (To Be):

- all the procedures should be well defined, highlighting the interactions among actors and clarifying the communication rules;

- Information exchange should take place on a BLM platform that contains the IFC model;

- All the actors, even the secondary ones, should use BLM tools to optimize exchange information time;

- The supervisory body, represented by the BLM manager, should have access to information during the whole construction process to verify that all the procedures are effectively respected;

- In the detailed design phase designers (architects, structural engineer, service engineer, safety engineer) should validate the project after clash detection;

- Each actor should have the access to the BLM model in a defined phase and should have the possibility to do defined operations;

- For each project a digital dossier should be automatically created, where maintenance data organization is standardised. Information about use phase can optimize energy consumption and expenditure and provide feedback.

\section{Findings}

The new process conceptual model (Fig. 2) scope is to give a solution to the issues related to the lack of interoperability among software and internal and external actors by using a common environment, where exchange of information is in real time and each actor uses standard formats. The interoperability concept that this work aims to is the level 3 of the technical roadmap adopted by BuildingSmart, an international organisation which aims to improve the exchange of information between software applications used in the construction industry ${ }^{1}$. The new system allows the transition from a traditional approach to an industrial one and from a consequential phases process to a circular phases process, where a global vision of the project during its life cycle is given by PLM principles. In this work, BLM is considered as a method which can close the gap between BIM and PLM maturity. In detail, instead of the different software applications used by the staff, a BLM platform, that enables communication among design, management and maintenance software, will be used. Furthermore, precise procedures and roles definition are established in order to guarantee traceability and a valid supervision method. Thanks to the new conceptual model, internal and external actors have a defined role in each phase of the process and are allowed to add information and manage the virtual model in according to standard procedures. For example, when construction works begin, designers have no longer access to virtual model information, but data will be available to next phases actors and to the BLM manager. During the construction phase the model is enriched by information added by building company and, at the end of this phase, only $3 \mathrm{~F}$ staff can manage data on BLM platform. Data

\footnotetext{
${ }^{1}$ http://buildingsmart.org/standards/technical-vision/technical-roadmaps/
} 
have to be structured in according to standard schemes and all the actors must use a unique language to avoid waste of time. System provides deadlines alerts and automatic checks of operations, as well as the opportunity to reduce the number of software applications used by the company, thanks to the possibility to manage different types of information on the same platform. The BLM manager is the supervisor of the entire process, who unifies all the phases and gives a common direction to company activities. All these considerations are made with a view to improve facility management phase, where an informative model of the building is the key to manage efficiently the building.

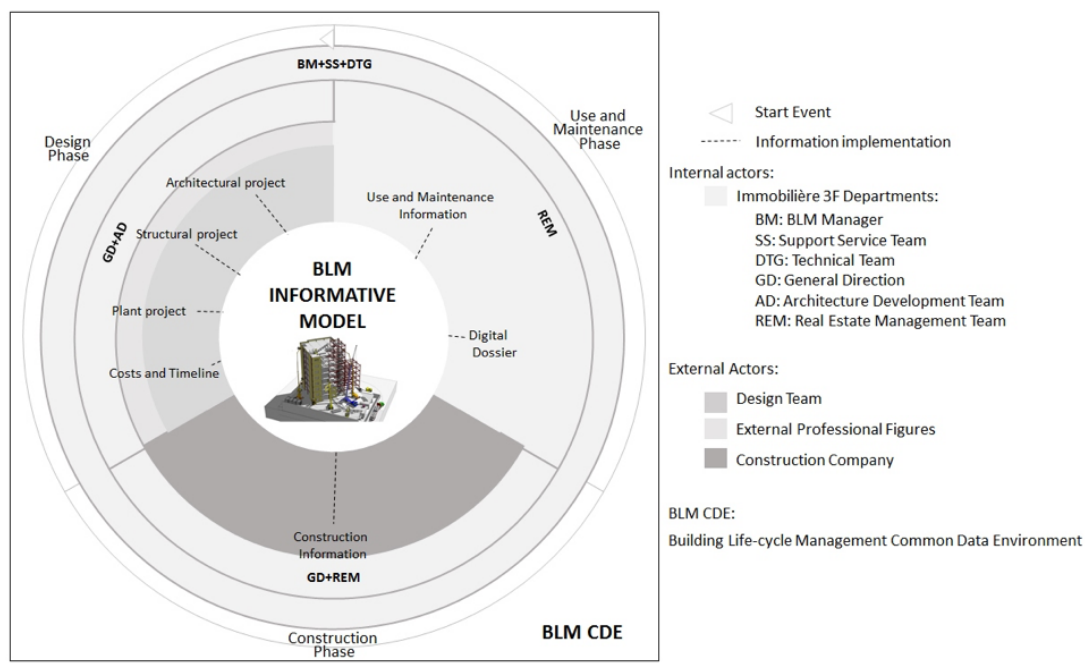

Fig. 2. "To Be"- Conceptual model of the company management process

\section{Conclusions and future developments}

The construction industry is taking a new and evolutionary phase, reshaping strategic visions, processes and products, thus supporting the implementation strategies of the BLM approach. An important role in this phase is played by information technologies that allow cooperation among all the process actors, interoperability, construction phase management and building maintenance management for the reduction of design errors and rework in construction and to optimize the real estate management. These benefits are due to an enriched platform, that correlate BIM and PLM features. The BLM environment gives life to new processes, resulting from the integration of different operative levels, and is able to activate and radically improve the productivity of the construction sector. PLM best practices, as result from literature study and as this empirical study confirms, are the key to bring innovation into a sector that is still linked to traditional approaches, far from industry 4.0 and circular economy concepts. BLM turns out to be the method that will innovate the management of building heritage as regards spaces, energy consumptions, maintenance. The present work results could be extended and 
adapted to other $3 \mathrm{~F}$ processes, like renovation process or urban renewal. This research is limited by the lack of a pilot case analysis to verify the effectiveness of the new conceptual model proposal. In addition to that, this work is referred to a process of data collection that took place in 2014, and because of this, it couldn't be possible to obtain information in subsequent stages of the qualitative analysis that could improve the accuracy of the study. To overcome the limitations of this research, it could be useful to evaluate a real case where a BLM approach is applied to $3 \mathrm{~F}$ activities. Another future development will be the application of this BIM/PLM integrated approach to the Regional Agency for house and living (ARCA) Social Housing management in Italy, considering the national context and customizing software and platform to the regional authority activities.

Acknowledgement The elaboration of this paper has been possible thanks to I3F, that permitted the study of its activities and gives useful information. We would like to thank Mariangela Lazoi, researcher at University of Salento, for her advice as regards PLM.

\section{References}

1. ENEA. Italy's Energy Efficiency Annual Report - Executive Report 2016.

2. World Economic Forum. Shaping the Future of Construction: A Breakthrough in Mindset and Technology. 2016. https://www.weforum.org/reports/shaping-the-future-of-construction-abreakthrough-in-mindset-and-technology.

3. Eastman, C. M. and al., et. BIM handbook: A guide to building information modeling for owners, managers, designers, engineers and contractors. s.1. : John Wiley \& Sons, 2011.

4. Panuwatwanich, et al. Factors affecting the current diffusion of BIM: a qualitative study of online professional network. Budapest : Creative Construction Conference, 2013.

5. Working Group UNI. CT033-GL05 Coding of products and processes in the building industry. 2017. approved parts 1,4 and 5 of the first standard Italian technique on BIM.

6. Jupp, J. R. and Nepal, M. BIM and PLM: Comparing and Learning from Changes to Professional Practice Across Sectors. s.1.: Springer Berlin Heidelberg, 2014. Vol. IFIP International Conference on Product Lifecycle Management.

7. Holzer, D. Fostering the Link from PLM to ERP via BIM. s.1. : Springer Berlin Heidelberg, 2014. Vol. IFIP International Conference on Product Lifecycle Management.

8. Jupp, J. R. and Singh, V. Similar concepts, Distinct solutions, Common problems: Learning from PLM and BIM Deployment. s.1. : Springer Berlin Heidelberg, 2014. Vol. IFIP International Conference on Product Lifecycle Management.

9. Stark, J. Product Lifecycle Management. 2nd. s.1. : Springer, 2011.

10. Amann, K. Product lifecycle management: empowering the future of business. s.1. : CIM Data, Inc., 2002.

11. Terzi, S., Bongiardina, C. and Macchi, M. Product Lifecycle Management: Definizione, caratteristiche e trend evolutivi. 2011.

12. den Otter, A., Pels, H.J. and Iliescu, I. BIM versus PLM: risks and benefits. Sophia Antipolis, Francia : s.n., 26-28 102011.

13. Succar, B. Handbook of research on Building Information Modelling and construction informatics: concepts and technologies. [ed.] J. Underwood \& U. Isikdag. Building Information Modelling maturity matrix. s.1. : Information Science Reference, IGI Publishing. pp. 65-103. 
14. Suermann, P. and Issa, R. Evaluating Industry Perceptions of Building Information modeling (BIM) impact on construction. ITcon, Journal of Information and construction. 2009, Vol. 14, pp. 574-594.

15. Carmona, J. and Irwin, K. BIM: Who, what,how and why. facilitiesnet.com. [Online] 2007. http://www.facilitiesnet.com/software/article/BIM-Who-What-How-and-Why--7546.

16. Reefman, R. J. B. and Van Nederveen, S. A Controlled Integral Product Model(IPM $\left.{ }^{\circledR}\right)$ in Building and Construction. Sophia Antipolis, Francia : s.n., 26-28 102011.

17. Jupp, J. R., \& Singh, V. A PLM perspective of BIM research initiatives. International Journal of Product Lifecycle Management. 2016

18. Jupp, J. R. Cross industry learning: A comparative study of product lifecycle management and building information modelling. International Journal of Product Lifecycle Management. 2016, Vol. 9(3), pp. 258-284.

19. Kim, H., et al. Generating construction schedules through automatic data extraction using open BIM (building information modeling) technology. Automation in Construction. 2013, 35, pp. 285-295.

20. Jupp, J. R. and Singh, V. Product Lifecycle Management for a Global Market. Similar Concepts, Distinct Solutions, Common Problems: Learning from PLM and BIM Deployment. s.1. : Springer Berlin Heidelberg, 2014. pp. 31-40.

21. Ustinovičiusa, L., et al. Innovative research projects in the field of Building Lifecycle Management. Procedia Engineering. 2015, 122, pp. 161-171

22. Froese, T. Future directions for IFC-based interoperability. [http://www.itcon.org/2003/17]. s.l. : ITcon, 2003. Vols. 8, Special Issue IFC - Product models for the AEC arena, pp. 231-246. 23. Migilinskasa, D., et al. The Benefits, Obstacles and Problems of Practical Bim Implementation. s.1. : Elsevier, 2013. Vol. 57 Procedia Engineering, pp. 767-774.

24. $\mathrm{Hu}, \mathrm{W}$. Information Lifecycle Modeling Framework for Construction Project Lifecycle Management. 2008. International Seminar on Future Information Technology and Management Engineering.

25. Liu, Q., Gao, T. and Wang-Jian, P. Study on Building Lifecycle Information Management Platform Based on BIM. Research Journal of Applied Sciences, Engineering and Technology. 2014, 7 .

26. Bricogne, M., et al. Building Lifecycle Management: overview of technology challenges and stakeholders. 2011.

27. Bouguessa, A., Forgues, D. and Doré, S. La complémentarité entre le Building Information Modeling (BIM) et le Product LifeCycle Management (PLM) en passant par le Lean Construction (LC). 2013. Vols. CSCE 2013 General Conference-Congrès général 2013 de la SCGC.

28. Aram, S. and Eastman, C. Integration of PLM solutions and BIM systems for the AEC industry. [compl.] Proceedings of the 30th ISARC. Montréal, Canada : s.n., 2013. pp. 1046-1055. 29. Holzer, D. Product Lifecycle Management for a Global Market. Fostering the Link from PLM to ERP via BIM. s.1. : Springer Berlin Heidelberg, 2014. Vol. 442, pp. 75-82.

30. Kassem, M., et al. Built Environment Project and Asset Management. BIM in facilities management applications: a case study of a large university complex. s.1. : Emerarld, 2015. Vol. 5, pp. 261-277.

31. Saaksvuori, Antti and Immonen, Anselmi. Product Lifecycle Management. s.1.: Springer, 2004. 